\title{
Mechanical tension in the median nerve. The effects of joint positions
}

\author{
G J Kleinrensink $M S^{1}{ }^{1}$, R Stoeckart $P h D^{1}, A$ Vleeming $P h D^{1}$, \\ C J Snijders $\mathrm{PhD}^{2}$, P G H Mulder $\mathrm{PhD}^{3}$
}

Departments of ${ }^{1}$ Anatomy, ${ }^{2}$ Biomedical Physics and Technology, and ${ }^{3}$ Epidemiology and Biostatistics, Faculty of Medicine, Erasmus University Rotterdam, The Netherlands

\begin{abstract}
Summary
Stretch tests are attractive in the diagnosis of nerve root or peripheral nerve lesion. Interpretation of the test results is often difficult since the distribution of tensile forces along the nerve caused by the test manoeuvre is not known. In this study the effect on median nerve tension of 22 positions of the arm was measured with 'buckle' force transducers. With the elbow in full extension and the hand in neutral position, altering the position of the shoulder significantly influenced tension in the proximal part of the median nerve; tension in the distal part was not influenced. With the shoulder in $90^{\circ}$ abduction, dorsiflexion of the hand combined with an extended elbow resulted in an increased tension in both distal and proximal parts of the median nerve. Dorsiflexion of the hand combined with flexion of the elbow caused an increase in tension only in the distal part. At all sites of the median nerve the median nerve upper limb tension test caused a significantly higher tension than the radial and ulnar nerve upper limb tension tests. This study provides insight in the normal distribution of tensile forces along the median nerve and can have clinical consequences. For differentiating nerve root from peripheral nerve lesions a specific provocative tension test for the median nerve is advocated. The results of this study provide a theoretical basis for differentiating between lesions in the proximal and distal parts of the median nerve.
\end{abstract}

\begin{abstract}
Relevance
In the diagnosis of nerve(root) lesions, tests in which stretching the nerve provokes the symptoms are widely used, but no data are available on the distribution of tensile forces along nerves and nerve roots during such tests. In this study a human cadaver model is presented to analyse tensile force distribution on the median nerve; it can be an aid to evaluate the specificity of a clinical provocation test for the median nerve.
\end{abstract}

Key words: Peripheral nerve, mechanical stress, (normal) articular range of motion, diagnosis

Clin. Biomech. Vol. 10, No. 5: 240-244, 1995

\section{Introduction}

In diagnosing nerve root lesions, several tests are available in which tensile forces provoke clinical symptoms (e.g. straight leg raising test). For two reasons the interpretation of test results is difficult. Firstly, no knowledge is available of the distribution of the tensile forces along nerve root and peripheral part of the nerve caused by normal upper extremity movements and test manoeuvres. Secondly, symptoms

Received: 20 July 1993

Accepted: 1 September 1994

Correspondence and reprint requests to: G.J. Kleinrensink Erasmus University Rotterdam, Dept. of Anatomy, Dr. Molewaterplein 50. 3015 GE Rotterdam, The Netherlands usually associated with nerve root lesions also can be caused by peripheral nerve lesions'. Thus problems arise in differentiating between nerve root lesions and lesions in the peripheral part of the nerve and in exactly localizing the site of nerve lesion.

As an analogon of the straight leg raising test, Kenneally et al. $^{2}$ proposed the "upper limb tension tests' (ULTT) for the median, ulnar and radial nerve. Also for these tests the distribution of tensile forces is not known. Thus empirical findings are clinically used without fundamental knowledge of the mechanical properties of the examined structures and knowledge of the specificity of tests.

In the present study 22 positions of the arm in the normal range of motion ( $\mathrm{RoM})$ are used to analyse the tensile forces at three sites of the peripheral part of the 
median nerve. The aim of this study is to provide a basis for a correct interpretation of clinical tests for the diagnosis of peripheral nerve lesions.

\section{Materials and methods}

Forty-eight to 60 hours after death, five human bodies were embalmed hy vascular perfusion with a medium containing 2.2\% formaldehyde. (For a detailed description of the fixation fluid see Kleinrensink et al. $1995^{3}$ ) The bodies were stored for 3 months in containers filled with phenoxy-ethanol at a temperature of $4^{\circ} \mathrm{C}$. After this period measurements were performed bilaterally $(n=10)$, at three sites on the median nerve: (1) in the axilla, about $2 \mathrm{~cm}$ distal to the bifurcation (Ax), (2) $2 \mathrm{~cm}$ proximal of the passage of the nerve through the pronator teres muscle (PP), and (3) at the wrist, $2 \mathrm{~cm}$ proximal to the styloid process of the radius (Wr). (Figure 1)

The measurements were performed under standardized conditions, including room temperature and air humidity.

\section{Test positions}

For the 18 positions in the normal RoM and the test positions used for the median, ulnar and radial nerve ULTT and a modified median nerve ULTT see Kleinrensink et al. $1995^{3}$ : Table la,b

All 22 joint positions were studied three times; as test and retest and after application of a tight band around the arm. The band was located at the site of the pronator teres muscle, simulating obstruction of the gliding mechanism of the median nerve. All tests were performed with the bodies lying supine, with neutral position of the cervical spine.

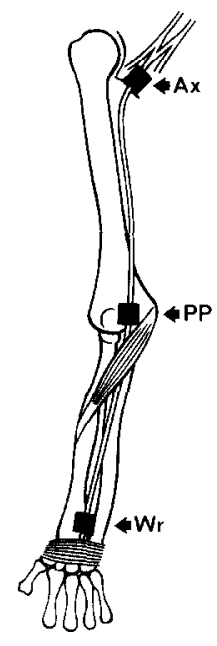

Figure 1. Position of the three buckle force transducers. $A \mathbf{x}=2 \mathrm{~cm}$ distal to the bifurcation (lateral and medial cord forming the median nerve), $\mathbf{P P}=2 \mathrm{~cm}$ proximal of the passage of the median nerve through the pronator teres muscle, $\mathbf{W r}=2 \mathrm{~cm}$ proximal to the styloid process of the radius.

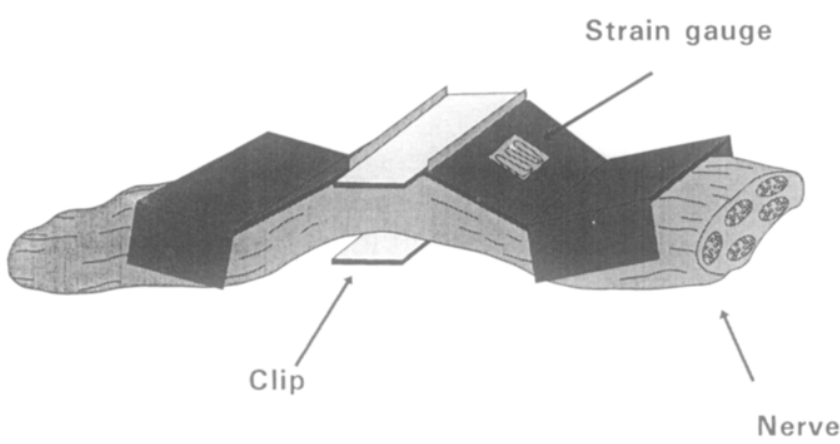

Figure 2. Buckle force transducer according to Peters ${ }^{5}$.

\section{Tension measurements}

'Buckle' force transducers ${ }^{4.5}$ were placed at Ax, PP, and Wr. The buckle transducer of Peters ${ }^{5}$ was designed for measuring stress and strain fields in ligaments. For attaching the transducer to the nerve, a stainless steel ' $U$ ' formed bar was constructed which locked the nerve in the transducer without initial damage. (Figure 2)

The transducer was extensively tested on nerve tissue and was shown to have a high test-retest reliability. To compensate for deformation by tensile stress the nerve-buckle transducer unit was calibrated after each measurement (see: Calibration procedure).

The signal from the buckle transducer was amplified by a bridge amplifier (made by the Department of Biomedical Physics and Technology) and led to a four-channel plotter.

\section{Calibration procedure}

To convert the transducer output from millivolt to newton, the nerve segment and transducer were simultaneously removed from the body by dissection and the transducers were calibrated for each measured nerve segment. Calibration was performed twice from 0 to $1000 \mathrm{~g}$ in steps of $100 \mathrm{~g}$. (correlation coefficient $>0.955$; mean standard error of estimation 0.04 , range $0.02-0.09)$.

\section{Statistical analysis}

All independent factors were considered fixed. Their levels are represented by dummy variables using reference coding in a multiple linear regression analysis.

\section{Results}

\section{Normal range of movement}

In relation to a reference position of $120^{\circ}$ flexion in the elbow, a position of $90^{\circ}$ shows no change in tension in the median nerve at the axilla ( $(\mathbf{A x})$, proximal to the pronator teres muscle (PP) and at the wrist (Wr).

Full extension of the elbow $\left(0^{\circ}\right)$ significantly increases tension in all three nerve segments (Table 1). Tension in all three segments is also significantly higher 
if full extension is compared to $90^{\circ}(P<0.01)$.

The $70^{\circ}$ (dorsiflexion) position of the hand differs significantly from the $0^{\circ}$ (neutral) position, whereas the $80^{\circ}$ (palmar flexion) position does not (Table 1). Compared to supination, pronation decreases the tension of the median nerve at PP and Wr but not at the Ax site.

\section{Median nerve and modified median nerve ULTT}

The median nerve ULTT and the modified median nerve ULTT are compared with a reference position (see Kleinrensink et $\mathrm{al}^{3}$ : position III.1.c, Tables 1a,b). In performing the median nerve ULTT, $20^{\circ}$ abduction, $10^{\circ}$ retroflexion, and $60^{\circ}$ external rotation is added to the reference position. This results in a significant increase in tension in the median nerve at $\mathrm{Ax}$ and PP.

Altering shoulder joint position to maximal abduction, maximal retroflexion, and maximal external rotation (modified median nerve ULTT) an even larger increase is found. Tension at the distal (Wr) site is not significantly influenced by altering the shoulder position (Table 2).

To analyse whether differences occur between the four testing manoeuvres, the original median nerve ULTT was taken as reference. At all three sites of the median nerve, the modified median nerve ULTT causes a significantly higher tension than the original median nerve ULTT. This in sharp contrast to the effects of the ulnar and radial nerve ULTT. (Table 3).

\section{Differentiation between lesions in the upper and lower} part of the median nerve

With the shoulder in $90^{\circ}$ abduction and the elbow in full extension, tension is significantly increased in all three segments by $70^{\circ}$ dorsiflexion of the hand. Dorsiflexion of the hand with $90^{\circ}$ flexion of the elbow causes a significant rise in tension only at the Wr site of the median nerve.

In these positions no difference between pronation and supination was observed (Table 4).

With a $90^{\circ}$ flexed elbow, $70^{\circ}$ dorsiflexion of the hand (if compared to the neutral position of the hand) causes a significant rise in tension only in the distal (Wr) part of the median nerve (Table 5).

In comparing the mean values of normal range of movement tension with those of the simulated pronator teres obstruction, no significant differences were found.

\section{Discussion}

Since Lasègue ${ }^{6}$ proposed a tension test for the sciatic nerve, this provocation test is a widely used tool in diagnosing lumbar radiculopathy. Recently several testing positions of the upper extremity have been proposed. They are supposed to stress the cervical nerve roots and thus could be used as provocation tests $^{2,7,8}$. The mentioned tests are based on the assumption that due to certain test manoeuvres, tension increases in a nerve root entrapped in the

Table 1. The effect of elbow and hand position on tension in three median nerve segments

\begin{tabular}{|c|c|c|c|c|}
\hline Tension & & Axilla & Pronator proximal & Wrist \\
\hline \multirow{2}{*}{$\begin{array}{l}\text { Elbow } \\
\text { reference } \\
120^{\circ} \text { (flexion) }\end{array}$} & $90^{\circ}$ & $\begin{array}{l}0.20 \\
\text { (SEM 0.49) }\end{array}$ & $\begin{array}{l}0.00 \\
\text { (SEM 0.59) }\end{array}$ & $\begin{array}{l}0.00 \\
\text { (SEM 0.59) }\end{array}$ \\
\hline & $0^{\circ}$ (extension) & $\begin{array}{l}8.73 \\
\text { (SEM 0.49) } \neq\end{array}$ & $\begin{array}{l}8.44 \\
\text { (SEM 0.59) }\end{array}$ & $\begin{array}{l}4.81 \\
\text { (SEM 0.59) }\end{array}$ \\
\hline \multirow{2}{*}{$\begin{array}{l}\text { Hand } \\
\text { reference } \\
0^{\circ} \text { neutral }\end{array}$} & $70^{\circ}$ dorsiflexion & $\begin{array}{l}3.04 \\
(\text { SEM } 0.49) \neq\end{array}$ & $\begin{array}{l}3.72 \\
\text { (SEM 0.59)‡ }\end{array}$ & $\begin{array}{l}8.34 \\
\text { (SEM 0.59) } \ddagger\end{array}$ \\
\hline & $80^{\circ}$ palmar flexion & $\begin{array}{l}-0.58 \\
\text { (SEM 0.49) }\end{array}$ & $\begin{array}{l}-0.59 \\
\text { (SEM 0.59) }\end{array}$ & $\begin{array}{l}-0.88 \\
\text { (SEM 0.59) }\end{array}$ \\
\hline $\begin{array}{l}\text { Reference } \\
\text { max. supination }\end{array}$ & pronation (maximal) & $\begin{array}{l}-0.39 \\
\text { (SEM 0.39) }\end{array}$ & $\begin{array}{l}-1.08 \\
\text { (SEM 0.49)§ }\end{array}$ & $\begin{array}{l}-1.28 \\
\text { (SEM 0.49)§ }\end{array}$ \\
\hline
\end{tabular}

Mean differences and SEM (in newton) with the reference level, taking into account all other factors in the model. $¥ P<0.001$; $\S P<0.05$

Table 2. Differences between upper limb tension test (ULTT)/modified ULTT and a reference position, comparable in elbow and hand position (see Kleinrensink et al. 1994 ${ }^{3}$, Table 1: pos.III.1c)

\begin{tabular}{|c|c|c|c|c|}
\hline Tension & & Axilla & Pronator proximal & Wrist \\
\hline $\begin{array}{l}\text { reference: } \\
\text { Elbow: } 0^{\circ} \\
\text { max supination }\end{array}$ & ULTT median nerve & $\begin{array}{l}8.53 \\
\text { (SEM 2.75) } \dagger\end{array}$ & $\begin{array}{l}10.01 \\
(\text { SEM 3.34)† }\end{array}$ & $\begin{array}{l}2.94 \\
\text { (SEM 1.86) }\end{array}$ \\
\hline $\begin{array}{l}\text { Hand: } 70^{\circ} \\
\text { (dorsiflexion) } \\
\text { (Table 1: pos. }(11.1 \mathrm{c})^{3}\end{array}$ & $\begin{array}{l}\text { Modified ULTT } \\
\text { median nerve }\end{array}$ & $\begin{array}{l}17.00 \\
\text { (SEM 2.75) } \neq\end{array}$ & $\begin{array}{l}18.44 \\
\text { (SEM 3.34)‡ }\end{array}$ & $\begin{array}{l}2.26 \\
\text { (SEM 1.86) }\end{array}$ \\
\hline
\end{tabular}

Mean differences and SEM (in newton) with the reference level of the factor. $\ddagger P<0.001 ; \dagger P<0.01$ 
Table 3. Differences between the originally suggested median nerve upper limb tension test (ULTT) and the modified median nerve ULTT, the ulnar nerve ULTT and the radial nerve ULTT

\begin{tabular}{|c|c|c|c|c|}
\hline Tension & & Axilla & Pronator proximal & Hand \\
\hline \multirow[t]{3}{*}{$\begin{array}{l}\text { reference: } \\
\text { ULTT median nerve }\end{array}$} & $\begin{array}{l}\text { Modified ULTT } \\
\text { median nerve }\end{array}$ & $\begin{array}{l}8.44 \\
\text { (SEM 2.94) } \dagger\end{array}$ & $\begin{array}{l}8.44 \\
\text { (SEM 3.04) } \dagger\end{array}$ & $\begin{array}{l}5.20 \\
\text { (SEM 2.16)§ }\end{array}$ \\
\hline & ULTT ulnar nerve & $\begin{array}{l}-23.15 \\
(\text { SEM 2.94)‡ }\end{array}$ & $\begin{array}{l}-25.11 \\
\text { (SEM 3.04) }\end{array}$ & $\begin{array}{l}-12.26 \\
\text { (SEM 2.16) }\end{array}$ \\
\hline & ULTT radial nerve & $\begin{array}{l}-14.72 \\
\text { (SEM 2.94) }\end{array}$ & $\begin{array}{l}-17.95 \\
\text { (SEM 3.04) }\end{array}$ & $\begin{array}{l}-17.17 \\
\text { (SEM 2.16)‡ }\end{array}$ \\
\hline
\end{tabular}

Mean differences and SEM (in newton) with the reference level of the factor. $¥ P<0.001 ; \dagger P<0.01 ; \S P<0.05$

Table 4. Differences between dorsiflexion of the hand combined with flexion in the elbow and dorsiflexion of the hand combined with extension (respectively with supination and pronation)

\begin{tabular}{|c|c|c|c|c|}
\hline Tension & & Axilla & Pronator proximal & Wrist \\
\hline $\begin{array}{l}\text { reference: } \\
\text { II.1. } c^{1}\end{array}$ & III. $1 . c^{2}$ & $\begin{array}{l}14.91 \\
\text { (SEM 1.47) } \neq\end{array}$ & $\begin{array}{l}16.00 \\
\text { (SEM 1.47) } \neq\end{array}$ & $\begin{array}{l}12.36 \\
\text { (SEM 2.16) }\end{array}$ \\
\hline $\begin{array}{l}\text { reference: } \\
\text { II.2. } c^{3}\end{array}$ & III. $2 . c^{4}$ & $\begin{array}{l}13.34 \\
\text { (SEM 1.37) }\end{array}$ & $\begin{array}{l}16.09 \\
\text { (SEM 2.75)‡ }\end{array}$ & $\begin{array}{l}10.70 \\
\text { (SEM 1.86) }\end{array}$ \\
\hline
\end{tabular}

Mean differences and SEM (in newton) with the reference level of the factor

'elbow: $90^{\circ}$ flexion, supination hand: $70^{\circ}$ dorsiflexion

${ }^{2}$ elbow: flexion, supination hand: $70^{\circ}$ dorsiflexion

${ }^{3}$ elbow: $90^{\circ}$ flexion, pronation hand: $70^{\circ}$ dorsiflexion

${ }^{4}$ elbow: extension, pronation hand: $70^{\circ}$ dorsiflexion

$\mp P<0.001$

intervertebral foramen. As a result of increased tension on the inflamed and irritated nerve root, the patient feels paraesthesia or pain in the sensory distribution area of the specific nerve.

However, in manipulating distal parts of an extremity the question arises whether tensile forces are actually transmitted all the way up to the nerve root. To answer this question, and to differentiate between peripheral nerve and nerve root lesions, detailed knowledge is required of the distribution of tensile forces in the test positions. Such a knowledge might explain why only half of the patients suffering from sciatica and characterized by a significant reduction of straight leg raising showed abnormal myelograms ${ }^{9}$. In these patients a lesion of the peripheral nerve, provoking symptoms generally associated with nerve root lesions, cannot be excluded.

Besides the question of how tensile forces are distributed along the median nerve, the aspect of the magnitude of tensile forces is of interest. Although to our knowledge actual tensile forces have not been analysed before, there is a large number of publications concerning the relation between stretching and tensile forces in peripheral nerves. In 1961 Sunderland $^{10}$ examined the relationship between clongation and upper limit of elasticity and mechanical failure in human cadaver studies. He found the mean percentage of elongation at the elastic limit to be $14 \%$ (range $8-21 \%$ ) and at mechanical failure to be $19 \%$ (range $7-31 \%$ ). More recently Kwan et al. ${ }^{11}$, in an in-vivo experiment, found that irreversible functional deficit occurred after strain of more than $12 \%$ of the in-situ strain of rabbit tibial nerve.

The present study was performed on embalmed human bodies; this can have certain influence on the tensile forces measured. Although the exact effects of embalmment on tensile forces on the median nerve have never been reported, certain changes in the collagen will take place. However, if compared to measurements on unembalmed specimens there appears to be a high positive correlation between data from unembalmed and embalmed human bodies ${ }^{3}$. So in the present work, which is a comparative study, the use of embalmed human bodies represents no specific problems.

From Table 1 it can be concluded that the position of the hand is relevant for the tension in the whole median nerve (including the proximal part). Tension in the $\mathrm{Ax}$ part is caused by dorsiflexion of the hand only when the elbow is extended $\left(0^{\circ}\right)$.

Full extension increases tension significantly in the middle and distal part of the median nerve (Table 1). Combined with the findings in Table 4 , this could be relevant in certain prolonged surgical procedures in which patients have to be in the supine position with fully abducted arm and extended elbow (e.g. radical mastectomy). Maintained tensile stress can be harmful to peripheral nerve ${ }^{11-13}$. The current study shows that tensile stress can be decreased by flexing the elbow to $90^{\circ}$ or $120^{\circ}$. The position of the shoulder is important for the tension in the middle as well as the proximal part of the median nerve (Table 2). Manipulating joints in the distal part of the upper extremity can increase nerve tension in the most proximal part of the median 
Table 5. Differences between dorsiflexion of the hand and neutral position, combined with flexion in the elbow (respectively with supination and pronation)

\begin{tabular}{|c|c|c|c|c|}
\hline Tension & & Axilla & Pronator proximal & Wrist \\
\hline $\begin{array}{l}\text { reference: } \\
\text { Il.1.b }\end{array}$ & II. $1 . c^{2}$ & $\begin{array}{l}0.20 \\
\text { (SEM 0.29) }\end{array}$ & $\begin{array}{l}0.000 \\
\text { (SEM 0.69) } \neq\end{array}$ & $\begin{array}{l}5.40 \\
\text { (SEM 0.88) }\end{array}$ \\
\hline $\begin{array}{l}\text { reference: } \\
\text { II. } 2 . b^{3}\end{array}$ & $11.2 . c^{4}$ & $\begin{array}{l}0.10 \\
\text { (SEM 0.39) }\end{array}$ & $\begin{array}{l}0.49 \\
\text { (SEM } 0.39 \text { ) }\end{array}$ & $\begin{array}{l}5.30 \\
\text { (SEM 0.98) }\end{array}$ \\
\hline
\end{tabular}

Mean differences and SEM (in newton) with the reference level of the factor

1 elbow: $90^{\circ}$ flexion, supination hand: $0^{\circ}$ (neutral)

${ }^{2}$ elbow: $90^{\circ}$ flexion, supination hand: $70^{\circ}$ dorsiflexion

${ }^{3}$ elbow: $90^{\circ}$ flexion, pronation hand: $0^{\circ}$ (neutral)

${ }^{4}$ elbow: $90^{\circ}$ flexion, pronation hand: $70^{\circ}$ dorsiflexion

$\ddagger P<0.001$

nerve (Table 1). However, changing the shoulder joint position does not alter nerve tension in the distal part of the median nerve (Table 2).

In all three parts of the median nerve both the ulnar and radial nerve ULTT cause a significantly lower tension than the median nerve ULTT (Table 3). These findings support the hypothesis that the ULTI for the median nerve is indeed specific for the median nerve. The modified median nerve ULTT is even more effective than the original median nerve ULTT (Table 3). The experiments were not performed on trunks and cords of the brachial plexus. It can be expected that tension values of the relevant cords do not significantly differ from the values of the upper part of the peripheral nerve. Preliminary data on tension in trunks and cords of the brachial plexus do indeed confirm this.

With extended elbow, dorsiflexion of the hand increases tension in all parts of the nerve. With flexed elbow, the same wrist position causes increase in tension only in the Wr part (Tables 4 and 5). Thus, in principle, differentiation between lesions in the upper and lower part of the median nerve is possible by manipulating specific joints. More evidence for the differentiation between lesions in the distal and proximal part of the median nerve must come from clinical investigations.

\section{Conclusions}

This study gives insight into the effects of joint positions on tensile forces of the median nerve; joint positions were compared with each other and the relative effects on tensile stress are discussed. Evidence is provided for the specificity of the ULTT for the median nerve. A rationale is offered for the manipulation of specific joints to differentiate between lesions in the proximal and distal parts of the median nerve.

\section{Acknowledgements}

The authors would like to thank J.V. de Bakker, D. Schot, and S. de Loor for their assistance in adapting and further developing buckle force transducer technology for nerve tension measurements, and D.H. Dietz, J.M. Gosens, M. v. Vendeloo, and R. Schenk for assisting in several pilot studies and the experiments on which this manuscript is based.

\section{References}

1 Mummenthaler M, Schliak H. Läsionen peripherer nerven. Diagnostik und Therapie. 4 edn. Thieme Verlag, Stuttgart, New York, 1982

2 Kenneally M, Rubenach H, Elvey R. The Upper limb tension test: the S.L.R. of the arm. In: R. Grant, ed., Physical Therapy of the Cervical and Thoracic Spine. Churchill Livingstone, New York, 1988

3 Kleinrensink GJ, Stoeckart R, Vleeming A et al. Peripheral nerve tension due to joint motion; a comparison between embalmed and unembalmed human bodies. Clin Biomech 1995; 10: 235-239 [this issue]

4 Salmons S. Eighth International Conference on Medical and Biological Engineering - Meeting Report. Biomed Eng 1969; 4: 467-74

5 Peters GWM. Tools for the measurement of stress and strain fields in soft tissues. Application to the elbow. [Thesis]. Limburg State University, The Netherlands, November 1987

6 Lasjgue C. Considerations sur la sciatique. Arch Gen de Méd Paris. $1864 ; 2$ : 558-80

7 Elvey RL. The treatment of arm pain associated with abnormal brachial plexus tension. Aust J Physiother 1986 32: $225-30$

8 Butler D. Adverse mechanical tension in the nervous system: a model for assessment and treatment. Aust $J$ Physiother 1989; 35: 227-38

9 Ken RSC, Cadoux-Hudson TA, Adanis CBT. The value of accurate clinical assessment in the surgical management of the lumbar disc protrusion. J.Neurol Neurosurg Psychiatry 1988; 51: 169-73

10 Sunderland S, Bradley KC. Stress-strain phenomena in human peripheral nerve trunks. Brain 1961; 84: 102-19

11 Kwan MK, Wall EJ, Massie J, Garfin SR. Strain, stress and stretch of peripheral nerve. Rabbit experiments in vitro and in vivo. Acta Orthop Scand 1992; 63: 267-72

12 Rydevik BL, Kwan MK, Myers RR et al. An in vitro mechanical and histological study of acute stretching on rabbit tibial nerve. J Orthop Res 1990; 8: 694-701

13 Lundborg G, Rydevik B. Effects of stretching the tibial nerve of the rabbit. A preliminary study of the intraneural circulation and the barrier function of the perineurium. $J$ Bone Joint Surg 1973; 55B: 390-401 